\title{
Rural-Urban Differences in Reasons for Incomplete Vaccination in Children Under Six Years, Southeast Iran 2013
}

\author{
Seyed Mehdi Tabatabaei ${ }^{1,}$; Tahere Mokhtari $^{2}$; Mohammad Salari ${ }^{2}$; Mehdi Mohammdi ${ }^{3}$ \\ 1 Infectious Diseases and Tropical Medicine Research Center, Booali Hospital, Zahedan University of Medical Sciences, Zahedan, IR Iran \\ ${ }^{2}$ Department of Primary Health Care Network Development, Sistan and Balouchistan Provincial Health Center, Zahedan University of Medical Sciences, Zahedan, IR Iran \\ ${ }^{3}$ Health Promotion Research Center, Zahedan University of Medical Sciences, Zahedan, IR Iran \\ *Corresponding author: Seyed Mehdi Tabatabaei, Infectious Diseases and Tropical Medicine Research Center, Booali Hospital, Zahedan University of Medical Sciences, Zahedan, IR \\ Iran. Tel: +98-54-33438801, Fax:+98-54-33438800, E-mail: zu.healthdeputy@gmail.com
}

Received: February 21, 2015; Revised: April 14, 2015; Accepted: May 3, 2015

\begin{abstract}
Background:Geographical differences in vaccination programs are a major public health problem, which is often linked to the availability of healthcare services and socioeconomic factors.

Objectives: The current study aimed to identify the differences in the patterns and the reasons for incomplete vaccination of children in urban and rural areas.

Patients and Methods: In the current cross-sectional study, a total of 1039 children under six years (612 rural and 427 urban subjects) were recruited from a databank of partially vaccinated children from March to December 2013. A group of trained Community Health Volunteers completed the study questionnaires by interviewing the parents of the identified children during their routine home visits. The Chi square test and Fisher's Exact test were used to compare the distribution of categorical variable between urban and rural areas. Results: The patterns of the number of missed doses of vaccine were similar for urban and rural subjects, but urban children 1 - 6 years were significantly more likely to miss subsequent doses of Oral Polio Vaccine (OPV) and Diphtheria-Tetanus-Pertussis (DTP). A statistically significant association was found between mother's age, place of birth and the number of missed vaccine doses. Rural healthcare providers more frequently disseminated vaccination information than urban vaccinators $(\mathrm{P}<0.001)$. A greater proportion of rural parents reported the lack of vaccines and healthcare staff misconduct as a reason for postponing vaccination, while over-crowdedness of health center, mother illness and forgetfulness, child illness and following physician recommendations were mentioned by a greater fraction of urban mothers.

Conclusions: Efforts to improve vaccination coverage should be taken into account regarding the differences in the factors that contribute to the incomplete vaccination status of children in the rural and urban areas. The current study findings indicate that vaccination services especially in the urban areas need to be reassessed to ensure that all children are covered. To develop and promote childhood vaccination strategies, special attention should be paid to address maternal barriers for children under-vaccination.
\end{abstract}

Keywords: Vaccination; Immunization; Rural Health Services; Urban Health Services; Iran

\section{Background}

Immunization is a well-established public health investment to reduce children illness, disability and death from vaccine-preventable diseases. According to the World Health Organization (WHO), it is estimated that vaccination prevents two to three million children deaths each year (1). In 2013, about 112 million infants worldwide were vaccinated with three doses of Diphtheria-Tetanus-Pertussis (DTP3) vaccine, with a coverage of $84 \%$ (1). However, the global vaccination coverage was constant for the past few years. It is estimated that 22.4 million children worldwide did not receive the three basic vaccinations (DTP3) during their first year of life, with the majority of those children living in the developing countries (2). Suboptimal vaccination is a major public health problem and it might result in resurgence of vaccine-preventable diseases (3).

To develop and improve the vaccination coverage strategies, it is necessary to identify the risk factors of non-up- take of immunization services. Two systematic reviews of the literature show that the most common reasons associated with under-vaccination were related to immunization systems followed by factors related to family characteristics $(4,5)$.

Another systematic review found that parental-childhood characteristics and healthcare structure-professional features were two main groups of factors contributing to under-vaccination (4). Some of the parental-childhood attributes included; low socioeconomic status, lack of knowledge about vaccine-preventable diseases, and sick child delays (4). Healthcare structure-professional characteristics linked to underuse of vaccination services were mistrust in medical information provided by the health center staff, healthcare providers misconduct, and lack of health infrastructures (4). Another identified systematic problem was lack of a reminding system about

Copyright (C) 2015, Infectious Diseases and Tropical Medicine Research Center. This is an open-access article distributed under the terms of the Creative Commons Attribution-NonCommercial 4.0 International License (http://creativecommons.org/licenses/by-nc/4.0/) which permits copy and redistribute the material just in noncommercial usages, provided the original work is properly cited. 
the subsequent doses of vaccines and short duration of vaccination sessions (6).

Few studies investigated the causes of vaccination dropouts in children in Iran. A study on the immunization status in children under two years showed that $17.8 \%$ of the children were under-vaccinated and in $41.4 \%$ of the fully vaccinated subjects a delay of more than one month in the vaccination was observed (7). The main reason included negligence of health care providers and child illness (7). The result of a study on vaccination coverage of DTP3 in children 12 - 24 months old showed that approximately $15 \%$ of children did not receive vaccines at the proper time or were not vaccinated (8). Factors contributing to delayed vaccination consisted of parents' education, family income, number of children in the family, birth order, and the type of family file in the healthcare center (active-inactive). Another study reported that lack of access to maternal healthcare services was the main reason of incomplete vaccination in children (9). Lack of time, and child illness were related to delayed vaccination in children. The delay was also associated with maternal age and the number of children in the family (10).

Establishment of a unique Primary Healthcare system in Iran resulted in a significant improvement in all aspects of the population's health including vaccination coverage (11). According to the Islamic Republic of Iran Multiple-Indicator Demographic and Health Survey (IrMIDHS) 2010, there was substantial progress in children vaccination, but the percentage of children completing the recommended vaccination schedule remains below the expected targets in rural areas and also few underprivileged provinces including Sistan and Balouchestan, Southeast Iran (12). The IrMIDHS results showed that in comparison with urban children, the vaccination coverage across all vaccines was lower in rural children and the greatest gap was reported regarding the first dose of Measles, Mumps and Rubella (MMR1) vaccine (93.47\% versus 97.20\%). Moreover, the vaccination coverage for children 12 - 23 months living in Sistan and Blouchetsan province was lower than 95\% for all vaccines except OPV1 (the first dose of oral polio vaccine administered at birth) (12).

\section{Objectives}

The current study aimed to identify barriers to completing full schedules of vaccination in children under six years old living in the urban and rural areas covered by Zahedan University of Medical Sciences.

\section{Patients and Methods}

This cross-sectional study was conducted from March to December 2013, in Zahedan, Khash, Iranshahr, Saravan, Nikshahr, Sarbaz, Konarak and Chabahar districts, in Sistan and Balouchestan province, Southeast Iran. The study population included children under six years old with incomplete vaccination. Children with one or more missing doses of vaccine(s) were considered as partially immunized.
According to a $16 \%$ difference in the proportion of reasons for delayed vaccination between urban and rural areas (estimated from a pilot study), $\alpha=0.05$ and $\beta=0.2$, the estimated sample size was calculated as 200 subjects for each area. To consider the effect of the study design the sample size was doubled for each group. As rural population was much more accessible, researchers decided to increase the rural sample to 1.5 times of the urban population.

The study subjects were recruited from a databank of partially vaccinated children identified through a large scale vaccination coverage promotion campaign in children under six years old. A multi-stage cluster sampling method was employed to identify the subjects. The number of subjects recruited from each district was determined using probability proportional to size based on the number of children under five years old vaccinated during a polio eradication campaign in the previous year.

A 76-item structured questionnaire was used for data collection. The study questionnaire consisted of five parts. The first section included questions on socio-demographic characteristics of the participants. The second section was asking questions regarding children's birth. The third part included questions on the vaccine doses received according the Iranian EPI based on the information recorded in the children's vaccination card. The fourth section included questions on the performance of health center regarding all aspects of vaccination services. The fifth section queried maternal and health center related factors for vaccination delay. A group of trained Community Health Volunteers completed the study questionnaires by interviewing the parents of the identified children during their routine home visits. Verbal consent was obtained before individual surveys were conducted.

The validity of the questionnaire was estimated by calculation of the Content Validity Ratio (CVR) and content validity index using the feedback from a panel of 10 experts including public health professionals, maternal and child healthcare experts and pediatricians. The questions with a CVR less than 0.62 were either modified or removed (13). The reliability of the questionnaire was established with a Kuder-Richardson 20 coefficient of 0.73 .

Categorical variables were presented as counts and percentages. The Chi-square test and Fisher's exact test were used to compare the distribution of categorical variable between the rural and urban areas. A P value $<0.05$ was considered significant for all analyses. To analyze the data SPSS version 20 (Chicago, IL) was used. The study was approved by Zahedan University of Medical Sciences Ethics Committee.

\section{Results}

The current study included 1039 partially vaccinated children under six years old, including 538 (51.8\%) boys and $501(48.2 \%)$ girls. A total of $612(58.9 \%)$ subjects lived in rural areas and 427 children (41.1\%) were residents of urban areas. The socio-demographic characteristics of the subjects are presented in Table 1. 
Tabatabaei SM et al.

\begin{tabular}{|c|c|c|c|}
\hline Variable & $\operatorname{Rural}(n=612)$ & $\operatorname{Urban}(n=427)$ & P Value \\
\hline Gender & & & 0.005 \\
\hline Male & $339(55.4)$ & $199(46.6)$ & \\
\hline Female & $273(44.6)$ & $228(53.4)$ & \\
\hline Age group & & & $<0.001$ \\
\hline$<1$ year & $139(22.7)$ & $58(13.6)$ & \\
\hline 1 - 2 years & $221(36.1)$ & $134(31.4)$ & \\
\hline 2 - 4 years & $154(25.2)$ & $160(37.5)$ & \\
\hline 4 - 6 years & $98(16.0)$ & $75(17.5)$ & \\
\hline Mother's age & & & 0.151 \\
\hline 25 years & $214(35.0)$ & $121(28.4)$ & \\
\hline $25-30$ years & $130(21.2)$ & $105(24.6)$ & \\
\hline $30-35$ years & $125(20.4)$ & $92(21.5)$ & \\
\hline 35 years & $143(23.4)$ & $109(25.5)$ & \\
\hline Father's age & & & 0.533 \\
\hline$<25$ years & $83(13.6)$ & $45(10.5)$ & \\
\hline $25-30$ years & $142(23.2)$ & $100(23.5)$ & \\
\hline 30 - 35 years & $124(20.2)$ & $89(20.8)$ & \\
\hline 35 years & $263(43.0)$ & $193(45.2)$ & \\
\hline Mother's age at marriage & & & 0.031 \\
\hline$<15$ years & $123(20.6)$ & $111(26.4)$ & \\
\hline 15 - 20 years & $348(58.2)$ & $242(57.5)$ & \\
\hline 20 years & $127(21.2)$ & $68(16.1)$ & \\
\hline Father's polygamy & & & 0.814 \\
\hline No & $542(88.6)$ & $381(89.2)$ & \\
\hline Yes & $70(11.4)$ & $46(10.8)$ & \\
\hline Mother's education & & & $<0.001$ \\
\hline Illiterate & $333(54.4)$ & $139(32.6)$ & \\
\hline Primary & $159(26.0)$ & $125(29.2)$ & \\
\hline Secondary school & $62(10.1)$ & $64(15.0)$ & \\
\hline High school & $51(8.4)$ & $75(17.6)$ & \\
\hline University & $7(1.1)$ & $24(5.6)$ & \\
\hline Father's education & & & $<0.001$ \\
\hline Illiterate & $203(33.2)$ & $79(18.5)$ & \\
\hline Primary & $171(27.9)$ & $114(26.7)$ & \\
\hline Secondary school & $125(20.4)$ & $104(24.4)$ & \\
\hline High school & $89(14.5)$ & $92(21.5)$ & \\
\hline University & $24(4.0)$ & $38(8.9)$ & \\
\hline Mother's occupation & & & $<0.001^{\mathrm{C}}$ \\
\hline Housewife & $604(98.7)$ & $405(94.8)$ & \\
\hline Government employee & $7(1.1)$ & $19(4.4)$ & \\
\hline
\end{tabular}


Tabatabaei SM et al.

\begin{tabular}{|c|c|c|c|}
\hline Worker & $1(0.2)$ & $3(0.7)$ & \\
\hline Father occupation & & & $<0.001$ \\
\hline Government employee & $59(9.6)$ & $81(19.0)$ & \\
\hline Worker & $232(37.9)$ & $107(25.1)$ & \\
\hline Self-employed & $235(38.4)$ & $201(47.1)$ & \\
\hline Unemployed & $86(14.1)$ & $38(8.8)$ & \\
\hline House ownership & & & $<0.001^{\mathrm{C}}$ \\
\hline Owner & $612(100.0)$ & $270(63.2)$ & \\
\hline Tenant & $0(0.0)$ & $97(22.8)$ & \\
\hline Others & $0(0.0)$ & $60(14.0)$ & \\
\hline Place of birth & & & $<0.001$ \\
\hline Maternity hospital & $278(45.6)$ & $324(76.4)$ & \\
\hline Delivery facilities & $143(23.5)$ & $50(11.8)$ & \\
\hline Home & $188(30.9)$ & $50(11.8)$ & \\
\hline Birth ranking & & & 0.890 \\
\hline First & $171(27.9)$ & $120(28.1)$ & \\
\hline Second & $122(19.9)$ & $93(21.8)$ & \\
\hline Third & $103(16.8)$ & 68 (15.9) & \\
\hline Forth and more & $216(35.3)$ & $146(34.2)$ & \\
\hline Household size & & & 0.637 \\
\hline$\leq 4$ & $248(40.5)$ & $170(39.8)$ & \\
\hline $5-6$ & $187(30.6)$ & $141(33.0)$ & \\
\hline$>6$ & $177(28.9)$ & $116(27.2)$ & \\
\hline $\begin{array}{l}\text { Having under six years siblings with } \\
\text { incomplete vaccination }\end{array}$ & & & $<0.001$ \\
\hline Yes & $265(43.5)$ & $255(59.9)$ & \\
\hline No & $344(56.5)$ & $171(40.1)$ & \\
\hline
\end{tabular}

\footnotetext{
${ }^{\mathrm{a}} \mathrm{n}=1039$.

$\mathrm{b}$ Values are presented as frequency (percent).

c PValues for Fisher's exact test.
}

In comparison with those living in urban areas, a greater proportion of rural children were under one year old (22.7\% versus $13.6 \%)$. Overall $37.5 \%$ of urban subjects were in the age group of -2-4 years, while this figure for rural children was $25.2 \%$, and the differences in the age group composition were statistically significant $(\mathrm{P}<0.001)$. Compared with rural mothers, urban mothers were more likely to get married at an age younger than 15 years (26.4\% versus $20.6 \%$ ), while marriage at older than 20 years was more frequent in mothers living in rural areas (21.2\% versus $16.1 \%, \mathrm{P}<0.031)$. A greater proportion of rural mothers were illiterate (54.4\% versus $32.6 \%$ ), while urban mothers dominated in all other educational levels and the difference was statistically significant $(\mathrm{P}<0.001)$. A significantly greater proportion of urban children were born in a maternity hospital (76.4\% versus $45.6 \%)$. On the other hand home deliveries were more frequent in rural children $(30.9 \%$ versus $11.8 \%, \mathrm{P}<$
0.001). As compared with rural subjects, partially vaccinated children in urban areas were more likely to have an under-vaccinated sibling under six years old $(59.9 \%$ versus $43.5 \%$ ).

No significant differences were observed among children under one year in the proportion of missed vaccine doses according to the Iranian Expanded Program on Immunization (Table 2). Regarding multiple doses vaccines, a greater proportion of dropouts were observed for all vaccines in the subsequent doses of vaccine. In terms of the number of missed doses of vaccine, also no differences were found between urban and rural subjects. The pattern of missed vaccines in children 1 - 6 years for multiple doses vaccine was similar to those of children under one year old. Children living in urban areas were significantly more likely to miss subsequent doses of OPV and DTP. The patterns of the number of missed doses of vaccine were similar among urban and rural dwellers. 
Tabatabaei SM et al.

\begin{tabular}{|c|c|c|c|c|c|c|}
\hline \multirow[t]{2}{*}{ Variable } & \multicolumn{3}{|c|}{$<\mathbf{1}, \mathrm{y}$} & \multicolumn{3}{|c|}{$1-6, y$} \\
\hline & Rural $(n=139)$ & Urban $(n=58)$ & P Value & Rural $(n=473)$ & $\operatorname{Urban}(n=369)$ & PValue \\
\hline \multicolumn{7}{|c|}{$\begin{array}{l}\text { Proportion of incomplete } \\
\text { vaccine doses }\end{array}$} \\
\hline BCG & $17(12.2)$ & $5(8.6)$ & 0.463 & $41(8.7)$ & $31(8.4)$ & 0.891 \\
\hline OPVO & $26(18.7)$ & $9(15.5)$ & 0.594 & $52(11.0)$ & $38(10.3)$ & 0.746 \\
\hline OPV1 & $14(10.1)$ & $8(13.8)$ & 0.450 & $28(5.9)$ & $32(8.7)$ & 0.123 \\
\hline OPV2 & $22(15.8)$ & $14(24.1)$ & 0.169 & $49(10.4)$ & $62(16.8)$ & 0.006 \\
\hline OPV3 & $46(33.1)$ & $22(37.9)$ & 0.515 & $93(19.7)$ & $95(25.7)$ & 0.035 \\
\hline OPV4 & NA & NA & NA & $285(60.3)$ & $225(61.0)$ & 0.832 \\
\hline OPV5 & NA & NA & NA & $460(97.3)$ & $363(98.4)$ & 0.277 \\
\hline DPT1 & $14(010.1)$ & $7(12.1)$ & 0.679 & $30(6.3)$ & $38(10.3)$ & 0.037 \\
\hline DPT2 & $21(15.1)$ & $9(15.5)$ & 0.942 & $49(10.4)$ & $64(17.3)$ & 0.003 \\
\hline DPT3 & $45(32.4)$ & $18(31.0)$ & 0.854 & $87(18.4)$ & $107(29.0)$ & 0.000 \\
\hline DPT4 & NA & NA & NA & $284(60.0)$ & $242(65.6)$ & 0.099 \\
\hline DPT5 & NA & NA & NA & $457(96.6)$ & $362(98.1)$ & 0.189 \\
\hline Hepatitis B1 & $15(10.8)$ & $3(5.2)$ & 0.212 & $40(8.5)$ & $26(7.0)$ & 0.450 \\
\hline Hepatitis B2 & $21(15.1)$ & $8(13.8)$ & 0.812 & $36(7.6)$ & $40(10.8)$ & 0.105 \\
\hline Hepatitis B3 & $48(34.5)$ & $17(29.3)$ & 0.477 & $96(20.3)$ & $85(23.0)$ & 0.337 \\
\hline MMR1 & NA & NA & NA & $151(31.9)$ & $113(30.6)$ & 0.686 \\
\hline MMR2 & NA & NA & NA & $300(63.4)$ & $250(67.8)$ & 0.191 \\
\hline \multicolumn{7}{|c|}{$\begin{array}{l}\text { Number of incomplete } \\
\text { vaccine doses in children } \\
<\text { one year (out of } 12 \text { doses) }\end{array}$} \\
\hline 1 & $59(42.4)$ & $24(41.4)$ & 0.682 & & & \\
\hline $2-3$ & $33(23.7)$ & $17(29.3)$ & & & & \\
\hline$>3$ & $47(33.8)$ & $17(29.3)$ & & & & \\
\hline \multicolumn{7}{|c|}{$\begin{array}{l}\text { Number of incomplete } \\
\text { vaccine doses in children } 1 \text { - } 6 \\
\text { years (out of } 17 \text { doses) }\end{array}$} \\
\hline$<5$ & $181(38.3)$ & $143(38.8)$ & 0.143 & & & \\
\hline $5-7$ & $200(42.3)$ & $136(36.9)$ & & & & \\
\hline$>7$ & $92(19.5)$ & $90(24.4)$ & & & & \\
\hline
\end{tabular}

a Abbreviations: BCG, Bacille Calmette-Guerin; DTP, Diphtheria-Tetanus-Pertussis; MMR, Measles-Mumps-Rubella; OPV, Oral Polio Vaccine.

$\mathrm{b}$ Values are presented as No. (\%).

Comparing categories of missed doses of vaccine in children under one year old according to different socio-demographic characteristics, a statistically significant association was found regarding mother's age group and birth place but no other variables (data not shown). Children of mothers in the age group greater than 35 years were less likely to have higher numbers of missed doses of vaccine. The proportion of children in the categories with one dose, -two to three doses and $>3$ doses of missed vaccine in this age group decreased from $44.7 \%$ to $36.8 \%$ and $18.4 \%$, respectively $(\mathrm{P}<0.007)$. A similar decreasing pattern was observed among the children born in a maternity hospital. Children born at home showed an increasing pattern across categories of missed vaccine doses $(\mathrm{P}<0.008)$. Children 1-6 years born in a maternity hospital or a delivery facility were far less likely to miss more than seven doses of vaccine compared with the ones born at home $(\mathrm{P}<0.001)$. As shown in Table 3, subjects living in rural areas were more likely to have an active household health file (i.e. the last visit to healthcare units no longer than three months ago), compared with those living in urban areas (60.9\% versus 39.1\%, $\mathrm{P}<0.005$ ). Rural healthcare providers more frequently disseminated vaccination information than urban vaccinators $(\mathrm{P}<0.001)$. Face-to-face vaccination training was more commonly used in rural healthcare centers, while group or class sessions were the predominant method of conferring information in urban healthcare centers $(\mathrm{P}<0.001)$. In comparison with urban mothers, mothers living in rural areas were more likely to lose their child's vaccination card ( $80.5 \%$ versus $19.5 \%, \mathrm{P}$ $<0.004$ ) and more likely not to carry the vaccination card when visiting healthcare center for vaccination. 
Tabatabaei SM et al.

\begin{tabular}{|c|c|c|c|}
\hline Variable & Rural $(n=612)$ & $\operatorname{Urban}(n=427)$ & P Value \\
\hline Type of household file & & & 0.005 \\
\hline Active & $516(84.3)$ & $331(77.5)$ & \\
\hline Non-active & $96(15.7)$ & $96(22.5)$ & \\
\hline Method of reaching healthcare center & & & $<0.001$ \\
\hline On foot & $423(69.1)$ & $298(69.8)$ & \\
\hline Their own vehicle & $149(24.3)$ & $84(19.7)$ & \\
\hline Public transportation & $12(2.0)$ & $38(8.9)$ & \\
\hline Others & $28(4.6)$ & $7(1.6)$ & \\
\hline Vaccine availability at healthcare center & & & $0.630^{\mathrm{b}}$ \\
\hline Always & $227(37.1)$ & $160(37.5)$ & \\
\hline Most of the time & $319(52.1)$ & $225(52.7)$ & \\
\hline Rarely & $59(9.6)$ & $40(9.4)$ & \\
\hline Never & $7(1.1)$ & $2(0.5)$ & \\
\hline Vaccinator presence & & & $0.308^{b}$ \\
\hline Always & $448(73.2)$ & $316(74.0)$ & \\
\hline Most of the time & $146(23.9)$ & $108(25.3)$ & \\
\hline Rarely & $17(2.8)$ & $3(0.7)$ & \\
\hline Never & $1(0.2)$ & $0(0.0)$ & \\
\hline Vaccinator providing vaccination information & & & $<0.001$ \\
\hline Always & $444(72.50$ & $289(67.7)$ & \\
\hline Most of the time & $153(25.0)$ & $107(25.1)$ & \\
\hline Rarely & $12(2.0)$ & $11(2.6)$ & \\
\hline Never & $3(0.5)$ & $20(4.7)$ & \\
\hline $\begin{array}{l}\text { Training methods used to improve mothers' vaccination } \\
\text { information }\end{array}$ & & & $<0.001$ \\
\hline Face-to-face & $602(98.4)$ & $397(93.0)$ & \\
\hline Group/class & $7(1.1)$ & $10(2.3)$ & \\
\hline None & $3(0.5)$ & $20(4.7)$ & \\
\hline Reminding the next vaccination appointment & & & 0.080 \\
\hline Always & $455(74.3)$ & $308(72.1)$ & \\
\hline Most of the time & $141(23)$ & $96(22.5)$ & \\
\hline Rarely & $13(2.1)$ & $15(3.5)$ & \\
\hline Never & $3(0.5)$ & $8(1.9)$ & \\
\hline Vaccination card issued & & & $0.066^{b}$ \\
\hline Yes & $604(98.7)$ & $426(99.8)$ & \\
\hline No & $8(1.3)$ & $1(0.2)$ & \\
\hline Vaccination card retention & & & 0.004 \\
\hline Yes & $579(94.6)$ & $419(98.1)$ & \\
\hline No & $33(5.4)$ & $8(1.9)$ & \\
\hline $\begin{array}{l}\text { Mother carrying vaccination card when visiting healthcare } \\
\text { center }\end{array}$ & & & 0.002 \\
\hline Always & $354(57.8)$ & $287(67.2)$ & \\
\hline Most of the time & $180(29.4)$ & $113(26.5)$ & \\
\hline Rarely & $58(9.5)$ & $20(4.7)$ & \\
\hline Never & $20(3.3)$ & $7(1.6)$ & \\
\hline Administered vaccines recorded in the vaccination card & & & $<0.001$ \\
\hline Always & $487(79.6)$ & $352(82.4)$ & \\
\hline Most of the time & $87(14.2)$ & $69(16.2)$ & \\
\hline Rarely & $19(3.1)$ & $5(1.2)$ & \\
\hline Never & $19(3.1)$ & $1(0.2)$ & \\
\hline
\end{tabular}


Regarding the reasons for delayed vaccination, a greater proportion of rural mothers reported the lack of vaccines and healthcare staff misconduct as a reason for postponing vaccination, while overcrowding of healthcare center was mentioned by a greater fraction of urban mothers and the differences were statistical- ly significant (Table 4). Mother illness and forgetting about next vaccination appointment, child sickness and following physician recommendations were significantly less likely to be the reason for delayed vaccination in rural children as compared with urban residents.

Table 4. Reasons for Delayed Vaccine Doses in the Children Under Six Years Old by Place of Residence a

\begin{tabular}{|c|c|c|c|}
\hline Variable & $\operatorname{Rural}(n=612)$ & Urban $(n=427)$ & PValue \\
\hline \multicolumn{4}{|l|}{ Healthcare center related factors } \\
\hline No vaccine available & & & $<0.001$ \\
\hline Yes & $366(59.8)$ & $185(43.3)$ & \\
\hline No & $246(40.2)$ & $242(56.7)$ & \\
\hline No vaccinator available & & & 0.352 \\
\hline Yes & $54(8.8)$ & $30(7.0)$ & \\
\hline No & $558(91.2)$ & $397(93.0)$ & \\
\hline Long distance to travel to the healthcare center & & & 0.077 \\
\hline Yes & $84(13.7)$ & $43(10.1)$ & \\
\hline No & $528(86.3)$ & $384(89.9)$ & \\
\hline Overcrowding of healthcare center & & & $<0.001$ \\
\hline Yes & $33(5.4)$ & $56(13.1)$ & \\
\hline No & $579(94.6)$ & $371(86.9)$ & \\
\hline Inappropriate timing of vaccination services & & & 0.062 \\
\hline Yes & $48(7.8)$ & $21(4.9)$ & \\
\hline No & $564(92.2)$ & $406(95.1)$ & \\
\hline Healthcare center staff misconduct & & & 0.038 \\
\hline Yes & $43(7.0)$ & $17(4.0)$ & \\
\hline No & $569(93.0)$ & $410(96.0)$ & \\
\hline Physician recommendations to postpone vaccination & & & $<0.001$ \\
\hline Yes & $80(13.1)$ & $100(23.4)$ & \\
\hline No & $532(86.9)$ & $327(76.6)$ & \\
\hline \multicolumn{4}{|l|}{ Mother and child related factors } \\
\hline Mother's sickness & & & 0.002 \\
\hline Yes & $59(9.6)$ & $70(16.4)$ & \\
\hline No & $553(90.4)$ & $357(83.6)$ & \\
\hline Mother forgetfulness & & & $<0.001$ \\
\hline Yes & $159(26.0)$ & $189(44.3)$ & \\
\hline No & $453(74.0)$ & $238(55.7)$ & \\
\hline Busy mom & & & 0.339 \\
\hline Yes & $90(14.7)$ & $73(17.1)$ & \\
\hline No & $522(85.3)$ & $354(82.9)$ & \\
\hline Travel & & & 0.096 \\
\hline Yes & $51(8.3)$ & $24(5.6)$ & \\
\hline No & $561(91.7)$ & $403(94.4)$ & \\
\hline Mother did know anything about the next dose & & & 0.204 \\
\hline Yes & $33(5.4)$ & $15(3.5)$ & 0.015 \\
\hline No & $579(94.6)$ & $412(96.5)$ & \\
\hline \multicolumn{4}{|l|}{ Child sickness } \\
\hline Yes & $106(17.3)$ & $101(23.7)$ & \\
\hline No & $506(82.7)$ & $326(76.3)$ & 0.131 \\
\hline \multicolumn{4}{|l|}{ Fear of adverse effects } \\
\hline Yes & $89(14.5)$ & $77(18.0)$ & \\
\hline No & $523(85.5)$ & $350(82.0)$ & \\
\hline
\end{tabular}




\section{Discussion}

The current paper examined a number of factors that influence the completeness of vaccination coverage for children younger than six years old in urban and rural areas of Sistan and Balouchestan province, Southeast Iran.

Regional differences between rural and urban vaccination coverage and uptake are common in both developed and developing countries. No significant differences were observed in vaccination coverage for urban and rural children under one year. In contrast, when looking at vaccination coverage for subjects between 1 - 6 years, it was found that children living in rural areas were far less likely to have missed vaccines than urban children. Comparing the contributing factors to incomplete vaccination, it was noted that health system related factors such as lack of vaccines and healthcare staff misconduct played an important role in children under-vaccination in rural areas. However, in the urban setting individual factors such as mother illness and forgetting about next vaccination appointments, child sickness and following physician recommendations were the major reasons for postponing vaccination. The data on reasons for differential vaccination coverage in urban and rural areas are scarce. The current study findings were consistent with those of a study on the determinants of timely vaccination among young children in Burkina Faso that showed rural children were more likely to have a timely vaccination for all vaccines (except for BCG) than urban children (14). A similar study in Iran found that the delay time in vaccination was longer in urban areas (15). Conversely, a study that investigated rural-urban differences in measles vaccination coverage among young Indonesian children showed that the first-dose of measles vaccine coverage in rural areas was lower as compared with that of the urban regions (68.5\% versus $80.1 \%$ ). Parental education and access to skilled healthcare providers were among the factors identified to be addressed to improve vaccination coverage in rural areas of Indonesia (16). A vaccination coverage survey among 12 - 23 month-old children in southern India, showed that the vaccination coverage in rural areas was lower for all vaccines, compared with vaccination coverage in the towns (17). The observed differences were attributed to the fact that vaccines in the towns were provided by private agencies that guarantee the availability of vaccines throughout the week and easy access, compared with government agencies that were the only source of vaccination services in rural areas.

A well-functioning health system is required for a good vaccination program (18). In the current study rural healthcare centers were found to provide better vaccination services. It was reflected in a greater proportion of active household health records, more regular vaccination services, more frequent information dissemination regarding vaccination and reminding mothers about the next vaccination appointment and more frequent follow up of missed vaccination appointments. The unique system of rural healthcare providers (Behvarz) in Iran plays an important role in providing quality healthcare services in a proactive, efficient, and inexpensive way (19). Behvarz who is local and lives in the same village motivates parents to make an early and sustainable linkage to the healthcare system. The continuity from prenatal care to institutional delivery can result in a better utilization of healthcare services and is found to be the most important factor regarding the complete vaccination of children (20). The number of regular visits to healthcare centers had an inverse correlation with vaccination delay time $(7,15)$. On the other hand, healthcare services in the urban areas of Iran are provided in a passive way and urban children rely on their mothers' initiative to get vaccinated. Mothers' failure to adhere to timely and complete vaccination of their children in the urban settings needs to be specifically addressed through proper intervention.

Numerous vaccine types were found to be missing among the studied urban and rural children. However, an important point regarding the multiple dose vaccines was the increase of missing the subsequent doses scheduled in the EPI. The dropouts were more prominent in the urban children aged 1 - 6 years. This finding illustrated the need for local health authorities to identify the factors affecting the missed deses and take necessary measures to bridge the gap in the vaccination-series coverage. The use of combination vaccines may simplify the vaccination schedule and increase the adherence of parents by reducing the number of visits to the vaccination unit(3).

In Children under one year, the number of missed vaccine doses was lower in mothers of the higher age groups compared with younger mothers. This is in agreement with the findings of some studies that suggest maternal age is an important factor associated with vaccine coverage and up-to-date vaccination coverage increases as maternal age increases (21). Maternal age could be considered as a proxy for the women's accumulated health literacy, which may have a positive influence on adherence to the full vaccination of children (22).

Child birth at a maternity hospital and delivery facilities were significantly associated with a lower proportion of incomplete vaccine doses. This is consistent with the results of the study that reported dropouts were less likely to occur in children born in a hospital (23). Mothers who give birth at a maternity hospital or a delivery facility are possibly more health conscious and hence more likely to have their children fully vaccinated.

Under-vaccinated urban children were more likely to have a sibling under six years old with incomplete vaccination, compared with rural children. Mothers with several children are likely to under-vaccinate their children (24). Some studies suggest that parental decisions but not inadequate availability of healthcare is a major determinant of delayed immunization (3). This finding further underlines the fact that parents can play an important 
role in gaining access to vaccination services for their children. Parents who are generally less educated and not aware of the health of their family members do not know the harmful effects of non-immunization. Moreover, the number of children in the family has a negative association with the vaccination coverage (8).

In summary, multiple reasons were identified for partial vaccination of rural and urban children. The current study indicated that a multi-faceted approach is needed to improve vaccination coverage in the Southeast of Iran. Vaccination program performance issues can be addressed through healthcare providers training and supervision.

\section{Acknowledgements}

The authors express their gratitude to the parents of under-vaccinated children who participated in the study. Authors are also thankful to the rural and urban healthcare center staff and Community Health Volunteers who helped with interviewing the participants and data collection.

\section{Authors' Contributions}

Study design and coordination in study conduction: Seyed Mehdi Tabatabaei; data collection and manuscript drafting: Tahere Mokhtari and Mohammad Salari the study; statistical analysis, data interpretation and paper drafting: Seyed Mehdi Tabatabaei ; technical consultations and critical revising the manuscript: Mehdi Mohammdi . Authors approved of the final draft of the paper.

\section{Funding/Support}

This study was funded by Zahedan University of Medical Sciences, Zahedan, Islamic Republic of Iran.

\section{References}

1. World Health Organization . Immunization coverage. World Health Organization 2014. Available from: http://www.who.int/ mediacentre/factsheets/fs378/en/.

2. World Health Organization .Immunization highlights: 2012. World Health Organization 2014. Available from: http://www.who.int/ immunization/newsroom/highlights/2012/en/.

3. Guerra FA. Delays in immunization have potentially serious health consequences. Paediatr Drugs. 2007;9(3):143-8.

4. Falagas ME, Zarkadoulia E. Factors associated with suboptimal compliance to vaccinations in children in developed countries: a systematic review. Curr Med Res Opin. 2008;24(6):1719-41.

5. Rainey JJ, Watkins M, Ryman TK, Sandhu P, Bo A, Banerjee K. Reasons related to non-vaccination and under-vaccination of children in low and middle income countries: findings from a sys- tematic review of the published literature, 1999-2009. Vaccine. 2011;29(46):8215-21.

6. Quaiyum MA, Gazi R, Khan AI, Uddin J, Islam M, Ahmed F, et al. Programmatic aspects of dropouts in child vaccination in Bangladesh: findings from a prospective study. Asia Pac J Public Health. 2011;23(2):141-50.

7. Hajizdeh S, Rezaie Pour A, Geranmayeh M, Kazem Nezhad A. Assessment Status of Immunization for Children Under 2 Years Old in Shahriar, Iran. Journal of Research in Health Sciences. 2011;4(1):11-21.

8. Dabiran S, Moghadam A. Status of Coverage of Dtp3 Vaccine and Related Factors, in children 12-24 months old in Tehran. Payavard Salamat. 2011;5(2):26-32.

9. Mahvari K, Zare S, Khorrami F. Evaluation of immunization and growth monitoring services to infant and the maternal knowledge in the Population Research Center in Bandar Abbas in 2004. Hormozgan Medical Journal. 2004;10(3):223-30.

10. Kamran A, Shahverdi A, Behzadifar M, Pirzadeh A. Factors influencing delayed immunization of children under eighteen months of age in Khorramabad. Health System Research. 2011;7(6).

11. Asadi-Lari M, Sayyari AA, Akbari ME, Gray D. Public health improvement in Iran--lessons from the last 20 years. Public Health. 2004;118(6):395-402.

12. Rashidian A, Khosravi A, Khabiri Nemati R, Khodayari Moez E, Elahi E, Arab M. Health Observatory: First report I.R. Iran MultipleIndicator Demographic and Health Survey 2010; 2012 Contract No.: Document Number. 2012.

13. Lawshe CH. A Quantitative Approach to Content Validity. Personnel Psychology.1975;28(4):563-75.

14. Schoeps A, Ouedraogo N, Kagone M, Sie A, Muller O, Becher H. Socio-demographic determinants of timely adherence to BCG, Penta3, measles, and complete vaccination schedule in Burkina Faso. Vaccine. 2013;32(1):96-102.

15. Poorolajal J, Khazaei S, Kousehlou Z, Bathaei S, Zahiri A. Delayed Vaccination and Related Predictors among Infants. Iran J Public Health. 2012;41(10):65-71.

16. Fernandez RC, Awofeso N, Rammohan A. Determinants of apparent rural-urban differentials in measles vaccination uptake in Indonesia. Rural Remote Health. 2011;11(3):1702.

17. Balraj V, Mukundan S, Samuel R, John TJ. Factors affecting immunization coverage levels in a district of India. Int J Epidemiol. 1993;22(6):1146-53.

18. Rwashana AS, Williams DW, Neema S. System dynamics approach to immunization healthcare issues in developing countries: a case study of Uganda. Health Informatics J. 2009;15(2):95-107.

19. Aghajanian A, Mehryar AH, Ahmadnia S, Kazemipour S. Impact of the rural health development programme in the Islamic Republic of Iran on rural-urban disparities in health indicators. World Hosp Health Serv. 2008;44(3):10-5.

20. Sia D, Fournier P, Kobiane JF, Sondo BK. Rates of coverage and determinants of complete vaccination of children in rural areas of Burkina Faso (1998-2003). BMC Public Health. 2009;9:416.

21. Salmon DA, Smith PJ, Pan WK, Navar AM, Omer SB, Halsey NA. Disparities in preschool immunization coverage associated with maternal age. Hum Vaccin. 2009;5(8):557-61.

22. Rahman M, Obaida-Nasrin S. Factors affecting acceptance of complete immunization coverage of children under five years in rural Bangladesh. Salud Publica Mex. 2010;52(2):134-40.

23. Shaikh S, Taj TM, Kazi A, Ahmed J, Fatmi Z. Coverage and predictors of vaccination among children of 1-4 years of age in a rural sub-district of Sindh. J Coll Physicians Surg Pak. 2010; 20(12):806-10.

24. Luman ET, McCauley MM, Shefer A, Chu SY. Maternal characteristics associated with vaccination of young children. Pediatrics. 2003;111(5 Pt 2):1215-8. 